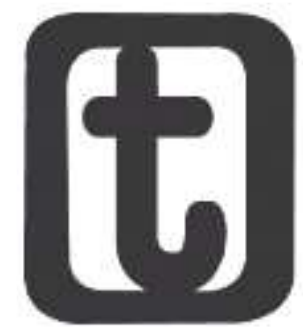

\title{
CONTRARREFORMA DO ESTADO, GERENCIALISMO E POLÍTICA DE ASSISTÊNCIA SOCIAL NO BRASIL
}

\author{
State contrarreform, managementism and social assistance policy in Brazil
}

\author{
Robson Roberto da Silva*
}

https://orcid.org/0000-0003-0699-853X

\section{RESUMO}

O presente trabalho, a partir de uma pesquisa bibliográfica e documental, que se orientou pelo materialismo histórico dialético, procura apresentar, por meio de uma discussão sobre a dimensão administrativa da contrarreforma do Estado e sua trajetória histórica no Brasil, os principais traços do gerencialismo na implementação da Política Nacional de Assistência Social de 2004, que apresenta um padrão de gestão do Sistema Único de Assistência Social.

\section{PALAVRAS-CHAVE}

Contrarreforma do Estado. Administração pública. Gerencialismo. Política de assistência social. Brasil.

\section{ABSTRACT}

The present work, based on a bibliographic and documentary research, which was guided by dialectical historical materialism, seeks to present, by means of a discussion on the administrative dimension of the State's counter-reform and its historical trajectory in Brazil, the main features of managerialism in Brazil. implementation of the 2004 National Social Assistance Policy, which presents a management model for the Unified Social Assistance System.

\section{KEYWORDS}

State counter-reform. Public administration. Managerialism. Social assistance policy. Brazil.

\section{INTRODUÇÃO}

ste trabalho é resultado dos estudos de pós-doutoramento, que vem sendo realizado em um Programa de Pós-Graduação em Serviço Social; e busca apreender a incidência do gerencialismo na implementação da Política Nacional de Assistência Social (PNAS) de 2004, que apresenta um padrão de gestão do Sistema Único de Assistência Social

\footnotetext{
* Assistente Social. Doutor em Serviço Social. Professor Adjunto da Escola de Serviço Social da Universidade Federal Fluminense. (UFF, Niterói, Brasil). Rua Prof. Marcos Waldemar de Freitas Reis, s/n Campus do Gragoatá, Bloco E, São Domingos Niterói, Rio de Janeiro (RJ), CEP: 24210-201. E-mail: robson.essuff@gmail.com.
}

DOI 10.22422/temporalis.2020v2on39p27-42 Commons Atribuição 4.0 Internacional (https://creativecommons.org/licenses/by/4.o/deed.pt_BR), que permite copiar e redistribuir o material em qualquer suporte ou formato, bem como adaptar, transformar e criar a partir deste material para qualquer fim, mesmo que comercial. O licenciante não pode revogar estes direitos desde que você respeite os termos da licença. 


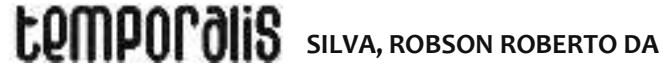

(SUAS). A compreensão sobre a administração/gestão pública ${ }^{1}$ no contexto da neoliberalização ${ }^{2}$ a partir de uma perspectiva crítica ainda é um campo teórico em construção, tendo em vista as perspectivas teórico-metodológicas em disputa. Como apontam Souza Filho e Gurgel (2016), as “[...] principais formulações, presentes hoje no debate, se aproximam da perspectiva do filósofo alemão Jürgen Habermas e/ou do pósmodernismo do cientista político Boaventura de Souza Santos [...]" (SOUZA FILHO; GURGEL, 2016, p. 14), e/ou das ideias da chamada terceira via, que preserva as premissas do neoliberalismo e que tem como um dos principais expoentes o sociólogo Anthony Giddens. Esse sociólogo defende um progressismo de livre-mercado com base em "[...] uma visão mais pragmática do Estado, valorizando a filosofia de livre-mercado do ponto de vista econômico e moral" (PAULA, 2005, p. 72).

Ao contrário desse pragmatismo, que corresponde ao modo de pensar a realidade na sua imediaticidade e de agir assim sobre ela, o estudo que deu origem a esse trabalho partiu da perspectiva do materialismo histórico dialético, que permite apreender a materialidade do Estado e da administração/gestão pública a partir das transformações que ocorrem na produção e na reprodução das relações sociais. Particularmente, no capitalismo, Mészáros (2015) aponta que "[...] a materialidade do Estado está profundamente enraizada na base sociometabólica antagônica sobre a qual todas as formações de Estado do capital são erguidas" (MÉSZÁROS, 2015, p. 29).

Nessa direção, cabe considerar que -, diferentes da classe dominante e suas frações que buscam propagar práticas e ideologias que justificam a utilização de concepções e mecanismos gerenciais, a partir de uma compreensão de crise como endógena ao Estado, que intervém e desperdiça demais, possui um modelo burocrático pouco moderno e eficiente -, é importante apreender a implementação do gerencialismo como parte inseparável do fenômeno cujos outros aspectos constituem a contrarreforma do Estado e o processo de reestruturação produtiva, que são respostas à crise estrutural do capital iniciada na década de 1970 (IASI, 2012).

Dardot e Laval (2016) apontam que o gerencialismo -, como um conjunto de técnicas e mecanismos oriundos da gestão de empresas, que é vista pelos seus defensores como a mais eficaz, flexível, inovadora, especializada e enxuta do que a administração pública burocrática - é considerado pelos seus formuladores e representantes como uma boa governança, exatamente por respeitar as condições de gestão sob o ajuste estrutural e a abertura aos fluxos comerciais e financeiros, o que demonstra a sua vinculação com uma política de integração ao mercado mundial.

De acordo com Coutinho (2010), os ideólogos do neoliberalismo apresentam-se hoje como defensores de uma suposta terceira via entre o liberalismo puro e a socialdemocracia estatista; e também como representantes de uma posição ligada às exigências da modernidade (ou da chamada pós-modernidade) e, portanto, ao progresso. Assim, Coutinho (2010) aponta que fazem da reforma ou mesmo da revolução (pois alguns defendem uma revolução liberal) suas principais bandeiras. Porém, o autor alerta que a palavra reforma esteve sempre ligada às lutas dos trabalhadores para transformar a

\footnotetext{
${ }^{1}$ Aguiar (2015), Souza Filho e Gurgel (2016) utilizam a palavra administração como sinônima de gestão.

2 Segundo Harvey (2008), “[...] a dinâmica evolutiva da neoliberalização tem agido de modo a forçar adaptações que variam muito de lugar para lugar e de época para época [...]” (HARVEY, 2008, p. 80), notando-se também desvios do modelo da teoria neoliberal.
}

Temporalis, Brasília (DF), ano 20, n. 39, p. 27-42, jan./jun. 2020. | ISSN 2238-1856 
sociedade e que o neoliberalismo vem utilizando a seu favor. Logo, "[...] o que antes da onda neoliberal queria dizer ampliação dos direitos, proteção social, controle e limitação do mercado etc., significa agora cortes, restrições, supressão desses direitos e desse controle: [um indiscutível processo de contrarreforma]" (COUTINHO, 2010, p. 35).

No Brasil, a Constituição Federal promulgada em 1988 incorporou em alguma medida as reivindicações dos setores progressistas. O texto constitucional adotou a noção de seguridade social (constituída pelas políticas de saúde, de previdência e de assistência social) e incorporou um conjunto de procedimentos legal-racionais, que favoreceriam a dimensão burocrática da administração/gestão pública. Destacam-se nesse caso os preceitos que buscam a profissionalização e a moralização do setor público e aqueles que podem contribuir para a democratização do poder, como a descentralização políticoadministrativa e a participação da população na gestão das políticas sociais. Contudo, com o projeto hegemônico neoliberal em curso desde os anos 1990, o termo reforma foi apropriado indebitamente pelos seus defensores; o seu significado e as mudanças que vêm ocorrendo a partir do uso pragmático desse termo distanciaram-se de qualquer conteúdo progressista (BEHRING, 2003).

Por essa razão, tem sido adotado o termo contrarreforma do Estado, que não deve ser restringida apenas a sua dimensão administrativa, posto que o gerencialismo é uma das dimensões da contrarreforma do Estado, que é constituída também pela contrarreforma econômica, fiscal, da previdência social etc. (BEHRING, 2003; SOUZA FILHO, 2011). Porém, nenhuma concepção de administração/gestão pública, que está associada ao desmonte do Estado e das políticas sociais, por si só tem este poder, sendo necessário compreender as determinações mais profundas, que estão associadas às alterações do padrão de acumulação capitalista e do Estado em um contexto de crise estrutural do capital (IASI, 2012).

Souza Filho (2011) destaca que a contrarreforma gerencial implementada no país vem contribuindo com o ajuste fiscal. Behring (2017), por sua vez, aponta que "[...] o Brasil convive há algumas décadas com uma espécie de ajuste fiscal permanente [...]" (BEHRING, 2017, p. 10), que tem sido imposto sob o discurso de combater um suposto déficit fiscal, quando na verdade busca contribuir com a apropriação privada do fundo público pelo capital de dominação financeira. Apesar da resistência dos setores à esquerda no espectro político, medidas de ajuste fiscal, privatização de empresas e serviços públicos, políticas sociais de alívio ou de enfrentamento à pobreza, portarias e leis que criminalizam os movimentos sociais e a pobreza, projetos aprovados de contrarreforma trabalhista, previdenciária e, não menos importante para o capital, propostas de contrarreforma da administração/gestão pública vêm impondo limites às conquistas democráticas.

Apesar de reconhecer aqui que a administração/gestão pública e a política de assistência social são resultados do confronto entre distintos projetos coletivos nessas áreas, que se articulam coerentemente a projetos de sociedade antagônicos, apresentando, portanto, respectivamente as marcas de uma unidade contraditória, o presente trabalho -, a partir de uma pesquisa bibliográfica e documental, que se orientou pelo materialismo histórico dialético -, procura, por meio de uma discussão sobre a dimensão administrativa da contrarreforma do Estado e sua trajetória histórica no Brasil, concentrar esforços na 
apresentação dos principais traços do gerencialismo na implementação da PNAS/SUAS de 2004.

\section{A DIMENSÃO ADMINISTRATIVA DA CONTRARREFORMA DO ESTADO BRASILEIRO E SUA TRAJETÓRIA HISTÓRICA}

No início dos anos 1990, o Brasil insere-se no atual estágio de internacionalização do capital. A integração da economia brasileira pela via da dependência e subalternidade a esse estágio marcado pela mundialização do capital só fez agravar a crise de natureza estrutural que o país experimentava há mais de duas décadas. Porém, segundo Bresser Pereira (2009), diferente da Grande Depressão de 1929, cuja causa fundamental foi o mercado, a crise que atingiu o mundo em 1970 é criação do Estado. Logo, para esse ex-ministro da Fazenda do governo Sarney, a crise econômica e fiscal exigia a necessidade de um Estado que administrasse com eficiência as empresas e os serviços sociais. Para tanto, não mediu esforços para defender uma organização político-administrativa, como aquela forjada por meio do Decreto-lei $n^{\circ} 200$, de 25/02/1967.

Nesse cenário a administração pública sofreu com um reformismo conservador, pois, por ser parte integrante do Estado e da sociedade, não passa ilesa as transformações sociais, como também se converte em meio/instrumento que visa satisfazer as necessidades no tocante à reprodução do capital. No primeiro discurso do presidente da República, Fernando Collor de Mello, em 1990, a proposta de reconstrução nacional apresentada assemelhava-se às medidas neoliberais, pois defendeu que a estabilização financeira dependeria de uma ampla reforma que reduzisse os gastos públicos, o tamanho do aparelho estatal e incentivasse a economia de mercado.

Portanto, ao compreender também a crise econômica como crise do Estado, Collor tratou de propor uma reforma e, assim, definir um novo padrão de intervenção do Estado na economia e no social. No documento Brasil: um projeto de reconstrução nacional encaminhado ao Congresso Nacional em março de 1991, Collor (2008) mencionava a necessidade de modificar a natureza do Estado e suas formas de atuação, de modo a tornálo menor, ágil e articulador dos agentes privados. Para tanto, o governo recomendava um conjunto de medidas neoliberais, como a proposta de Reforma Administrativa, que buscava diminuir a intervenção do Estado na economia e na vida dos cidadãos, por meio da redução do tamanho das máquinas burocráticas, consideradas improdutivas e patrimonialistas.

Entretanto, as constantes denúncias de corrupção e a má administração do governo Collor levaram o Congresso Nacional a abrir uma Comissão Parlamentar de Inquérito, que resultou no impeachment desse presidente em setembro de 1992. Seu vice, Itamar Franco, assumiu a direção do país. Neste governo "[...] não houve maiores debates em torno da reforma administrativa e as ações foram bastante tímidas: criou-se o Conselho Administrativo de Defesa Econômica (CADE); a Agência Espacial Brasileira; o Departamento Nacional da Produção Mineral; a Secretaria Federal de Controle" (LIMA JUNIOR, 1998, p. 17). A maior preocupação do presidente Itamar Franco foi a de implantar o Plano Real, que seguia o programa de estabilização proposto pelo Fundo Monetário Internacional (FMI) e as reformas recomendadas pelo Banco Mundial. Na condução deste Plano estava o ministro da Fazenda, Fernando Henrique Cardoso (FHC), que venceu a eleição para a presidência da República em 1994. 


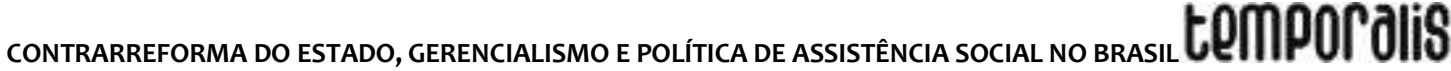

Ao assumir a presidência da República, em 1995, FHC procurou dar continuidade, como aponta Antunes (2005), à integração servil e subordinada do país à ordem mundializada, por meio da financeirização, da desindustrialização e da privatização de empresas, que haviam sido criadas pelos operários no período varguista. A consequência dessa reestruturação produtiva expressou-se no agravamento da pobreza e da desigualdade, à medida que aumentou o desemprego, a precarização do trabalho e a destruição dos direitos sociais.

Tais mudanças acabaram também contribuindo para a desorganização e fragmentação da luta da classe trabalhadora, o que foi um facilitador para que o governo FHC impusesse a contrarreforma da previdência social, fiscal e da administração pública, que significou como menciona Behring (2003) uma verdadeira "[...] contrarreforma do Estado, que implicou um profundo retrocesso social, em benefícios de poucos" (BEHRING, 2003, p. 22). A respeito da contrarreforma administrativa, $\mathrm{FHC}$, no seu primeiro dia de governo, publicou a Medida Provisória $n^{\circ}$ 813, de 01/01/1995, que dispõe sobre a organização da presidência da República e dos ministérios. Por meio desse instrumento, criou o Ministério da Administração e da Reforma do Estado (MARE), que seguiu as proposições contidas no Plano Diretor da Reforma do Estado (PDRAE). Tal Plano buscava transformar a administração pública brasileira de burocrática para gerencial. Porém, este Plano não se restringiu a essa dimensão da contrarreforma do Estado, tendo em vista que a "[...] 'reforma' administrativa [é] apenas um aspecto deste processo amplo. O Plano Diretor vai muito além da reforma administrativa. Tratou-se de uma revisão do conceito de Estado e uma refundação da relação Estado-sociedade" (BEHRING, 2003, p. 178).

Bresser Pereira, ex-ministro da fazenda do governo Sarney, também assumiu em 1995 a direção do MARE e foi considerado o principal mentor dessa contrarreforma do Estado e da administração pública. Nos cadernos do MARE sobre a reforma do Estado, este ministro manteve a sua compreensão de que o Estado é o principal causador da crise econômica. Por esse motivo, defendeu uma reforma (leia-se contrarreforma), que delimitasse o tamanho do Estado, redefinisse o seu papel regulador, recuperasse a governança e aumentasse a governabilidade.

Neste sentido, na sua concepção, a resposta à crise do Estado deveria estar pautada: na implantação de políticas voltadas para garantia do ajuste fiscal -, que, segundo Behring (2017), há algumas décadas no país tem sido permanente e "[...] vem implicando um nítido esvaziamento e mal-estar do Estado Democrático de Direito [...]” (BEHRING, 2017, p. 10) -; na alteração das formas de intervenção estatal na área econômica e social, por meio da contratação das chamadas organizações públicas não-estatais; e na realização de uma reforma administrativa gerencial que levasse o Estado a atuar como um regulador e facilitador do desenvolvimento econômico e social.

Em muitos países como o Brasil criaram ministérios e comissões encarregadas para realizar contrarreformas dessa natureza, que contaram com recursos financeiros emprestados pelo Banco Mundial e pelo Banco Interamericano de Desenvolvimento (BID). De acordo com Bresser Pereira (1997), quatro são os componentes básicos dessa reforma defendida por ele para o Brasil: i) delimitação das funções do Estado, que ocorre através da privatização, terceirização e publicização (essa última compreendida como transferência de responsabilidades dos serviços sociais e científicos ao chamado setor público não- 
estatal); ii) a redução do grau de interferência do Estado, que exige a sua desregulamentação como forma de transformá-lo em um fomentador da capacidade de competição do país no âmbito internacional (a ideia é a de que o Estado deve desregular para reduzir a intervenção do Estado e para viabilizar a privatização); iii) o aumento da governança do Estado, que corresponde à ampliação da capacidade de efetivar as decisões do governo por meio do ajuste fiscal; iv) e da governabilidade, que se refere-se à capacidade política de governar e deriva-se da relação de legitimidade do Estado e do governo com a sociedade.

Esses quatro componentes foram colados em prática durante os dois governos FHC (19952002), com a participação do ex-ministro do MARE, Bresser Pereira, que assumiu esta pasta no primeiro mandato (1995-1998), e têm sido implementado com algumas variações até os dias atuais. Entretanto, a implementação desses mecanismos gerenciais não superara as formas mais marcantes do padrão burocrático-patrimonialista, em alguma medida acabaram reforçando o patrimonialismo, e não ocorreu livre de resistência por parte dos setores que defendem a construção de um padrão democrático de administração/gestão pública. Como apontam Souza Filho e Gurgel (2006),

O gerencialismo do governo FHC, portanto, estrutura-se possibilitando a manutenção da dominação tradicional. Não suprime nem supera 0 patrimonialismo. Na verdade, como vimos, a contrarreforma administrativa, através da dimensão flexível/gerencial, repõe o patrimonialismo sobre outras bases (SOUZA FILHO; GURGEL, 2006, p. 185).

Nas áreas sociais, o gerencialismo nos governos $\mathrm{FHC}$ tratou de levar à lógica e às práticas de gestão das empresas para a gestão das políticas sociais. Souza Filho e Gurgel (2006) demonstram que os hospitais, os postos de saúde e as escolas públicas passaram a ser tratadas como empresas, com estabelecimento de metas, fixações de um tempo-padrão, seguindo a mesma lógica de uma fábrica. Particularmente, nas escolas foram criados índices de desempenho que consideram quantidade definidas de aprovação de estudantes como produção-padrão. Nos casos em que hospitais, unidades básicas de saúde e escolas estão submetidos a Organizações Sociais (OSs), essa lógica é ainda mais acentuada e registra maiores distorções, como contratos com cooperativas de trabalho irregulares, compras e serviços superfaturados, desvios de recursos públicos e abandono de unidades consideradas deficitárias pelos agentes privados.

A contrarreforma gerencial das políticas sociais nos governos $\mathrm{FHC}$ avançou com a aprovação e utilização de mecanismos de ajuste, como: a Lei de Responsabilidade Fiscal, $\mathrm{n}^{\circ}$ 101, de 4 de maio de 2000, que permite desde então que os governos, em nome da austeridade, cortem gastos, como os investimentos das áreas sociais, exceto os relacionados à dívida pública; e a renovação também em 2000 do Fundo de Estabilização Fiscal, que havia sido criado em 1994 como parte do Plano Real e que passou a ser denominado de Desvinculação das Receitas da União (DRU). Esse mecanismo retirava, a cada ano, 20\% dos recursos dos fundos públicos, incluídos os destinados à seguridade social, para honrar com o pagamento de juros e encargos da dívida pública. Por meio dele, o governo FHC diminuiu ainda mais os gastos sociais, para valorização e acumulação do capital; e buscou assim ampliar, em detrimento das políticas sociais permanentes e universais, os programas emergenciais de enfrentamento à pobreza absoluta (como os de transferência de renda condicionada), cujas funções têm sido delegadas aos estados e, principalmente, aos municípios. 
Luiz Inácio Lula da Silva, desde os anos 1980, defendia nas suas campanhas eleitorais à presidência da República pelo Partido dos Trabalhadores (PT) uma reforma democrática da administração pública, pautada na descentralização do poder. Sua vitória na eleição nacional de 2002 expressou o descontentamento dos trabalhadores e de frações da burguesia nacional com a política econômica implementada pelo governo FHC e também as transformações societárias que contribuíram com o processo de perda de referência política e ideológica de alguns setores à esquerda no espectro político no país, particularmente dos dirigentes desse partido político.

Durante os dois governos Lula, a neoliberalização seguiu a via do social-liberalismo, que ocupou também posições-chave na política econômica e social nos governos da sua sucessora, Dilma Rousseff, também eleita à presidência da República pelo PT em 2010. (CASTELO, 2012). De acordo com Mota (2012), esta ideologia é coroada pela apologia ao novo desenvolvimentismo fundado no equilíbrio entre crescimento econômico e desenvolvimento social, que do ponto de vista prático reduziu a pobreza absoluta, viabilizou o acesso mercantil a bens e serviços, sem, contudo, alterar os índices alarmantes das desigualdades.

Segundo Souza Filho e Gurgel (2016), existem polêmicas quanto à implementação ou não de um projeto neodesenvolvimentista pelo PT, que reproduziu a base política firmada no pacto conservador; manteve o chamado tripé macroeconômico; subsidiou o grande capital industrial; fortaleceu o capital financeiro; potencializou a exportação de commodities, pautada no agronegócio; negligenciou a expansão das políticas sociais estruturais; expandiu a assistência social através dos programas de transferência de renda condicionada; e não alterou o perfil da contrarreforma administrativa implementada pelos governos nacionais anteriores, que avançou através da contrarreforma da previdência do setor público, da criação das fundações estatais, da transferência de serviços sociais para as OSs e da transferência dos hospitais universitários para a Empresa Brasileira de Serviços Hospitalares (EBSERH). Ainda de acordo com os autores:

a produção documental dos governos do PT não deixa dúvidas acerca do caráter gerencialista que predomina na gestão petista da reforma administrativa. Em análise de vários documentos produzidos pelos governos do Partido dos Trabalhadores, Vargas (2012) também demonstra as afinidades dos conteúdos desses documentos com os princípios gerencialistas presentes no PDRAE, comandado por Bresser-Pereira (SOUZA FILHO; GURGEL, 2016, p. 187, grifos nossos).

Paula (2005) aponta que o gerencialismo orienta-se pela perspectiva estruturalfuncionalista e que, apesar das expectativas de construir uma administração pública democrática com a chegada do PT à presidência da República, o que se observou "[...] é uma continuidade das práticas gerencialistas em todos os campos, inclusive no que se refere às políticas sociais" (PAULA, 2005, p. 37).

A aprovação do pedido de admissibilidade do processo contra a presidente Dilma Rousseff na Câmara dos Deputados em 2016, sem a devida comprovação de crime de responsabilidade fiscal, configurou-se como um golpe travestido de legalidade, que também contou com o aval do Supremo Tribunal Federal, de setores do Judiciário, da Polícia Federal e da grande mídia. Assim, foi aprovado neste mesmo ano o impeachment 
dessa presidente. Sua deposição e a posse do seu vice, Michel Temer (que participou dos esquemas que deslocaram a base de apoio do governo) demonstraram uma transição pelo alto, que desrespeitou os preceitos democráticos constitucionais.

A partir desse trágico episódio, iniciou-se um período da história do país, marcado pelo aumento do (neo)conservadorismo e pela utilização de medidas neoliberais ortodoxas, que buscam atender os interesses do capital (inter) nacional e na mesma medida negligenciar as reais necessidades da maioria trabalhadora. Entre as medidas conservadoras deste governo ilegítimo, Silva (2018) destaca: a aprovação da Emenda Constitucional - EC 93/2016 (construída no governo Dilma), que prorrogou a DRU até 2023 e aumentou seu percentual de 20\% para 30\%; a aprovação da EC n 95, de 2016 (conhecida também como PEC do Teto dos Gastos Públicos), que instituiu um novo ajuste fiscal e que estabeleceu um limite/teto para as despesas primárias por um período de 20 anos; o pacote de medidas macroeconômicas, que também penalizam os trabalhadores; a Lei da Terceirização, $n^{\circ}$ 13.429/31 de março de 2017, que regulamenta a prática e permite que as empresas terceirizem até mesmo as atividades-fim; os projetos de contrarreforma trabalhista e da previdência social.

Em cumprimento ao novo ajuste fiscal, que são sucessivos e permanentes na neoliberalização (BEHRING, 2017), a primeira Medida Provisória (MP), de $n^{\circ} 726 / 2016$, que o presidente ilegítimo Temer assinou foi a referente à reforma administrativa, que previa corte de ministérios, com a extinção e a fusão de pastas, a partir da utilização de critérios meramente econômicos e burocráticos, que expressavam o desprezo desse governo com as áreas sociais. A exemplo, com este ato, esse governo determinou que o Ministério das Mulheres, da Igualdade Racial e dos Direitos Humanos fosse transferido para a alçada da Secretaria de Governo, e que ocorresse a fusão do Ministério do Desenvolvimento Social e Combate à Fome (MDS) com o Ministério do Desenvolvimento Agrário, dando origem ao chamado Ministério do Desenvolvimento Social.

A proposta de plano de governo do candidato à presidência da República da extrema direita, Jair Messias Bolsonaro, eleito em outubro de 2018 pelo Partido Social Liberal (PSL), também propõe uma contrarreforma administrativa, pautando-se numa concepção de gestão pública que considera moderna e que visa o controle dos gastos e a eficiência do Estado, de modo a torná-lo mais ágil. Aqui cabe dizer que a vitória desse candidato deve ser compreendida à luz dos processos estruturais e conjunturais que ocorrem no mundo e em particular no Brasil. A crise estrutural do capital, o fracasso dos governos de conciliação de classe, a falta de estabilidade do governo ilegítimo que seguiu ao golpe institucional, a dificuldade da direita golpista de encontrar uma alternativa eleitoral viável e a desarticulação do PT contribuíram para o fortalecimento da extrema direita como alternativa reacionária, que deslocou a responsabilidade pela crise e suas consequências para os seus adversários, com a utilização de mentiras e propagandas falsas, que se assemelham aos instrumentos do fascismo (IASI, 2018). Contudo, a vitória do Bolsonaro à presidência da República não significou o fim das lutas sociais. A resistência democrática e social que se formou no país, contrária a esse candidato e ao seu programa de governo, vem lutando contra os ataques que buscam liquidar as garatias democráticas e os direitos sociais, como a PEC Teto dos Gastos Públicos, a DRU, a lei da terceirização, a contrarreforma trabalhista, da previdência social e a proposta de contrarreforma administrativa que está sendo construída e que procurará alterar a forma de contratação 


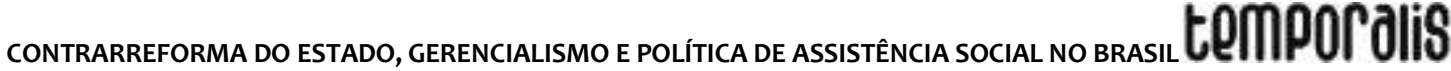

de servidores, o número de carreiras, a remuneração e outros aspectos da administração pública.

\section{AS PRINCIPAIS INCIÊNCIAS DO GERENCIALISMO NA IMPLEMETAÇÃO DA PNAS/SUAS}

Ao longo do século XX a assistência social no Brasil não tinha o status de política pública, apenas com a Constituição Federal de 1988 tornou-se um dever do Estado e um direito do cidadão. Esta Carta Constitucional alterou legalmente o padrão de proteção social, tendo em vista que, ao incluir a política de saúde, de previdência e de assistência social, como pilares da seguridade social, estabeleceu, ao menos formalmente, um formato de proteção social mais abrangente, inclusivo e com uma orientação democrática e redistributiva. A partir desse momento o marco jurídico-normativo dessa política social (Lei Orgânica da Assistência Social - LOAS, $n^{\circ}$ 8.742, de 7 de dezembro de 1993; a PNAS, de 2004; a Lei de $\mathrm{n}^{\circ}$ 12.435, de 6 de julho de 2011 - conhecida como Lei do SUAS; normas operacionais etc.) construído a partir da disputa entre diferentes projetos coletivos, tem estabelecido que as ações sócio assistenciais devam ser organizadas através de um sistema descentralizado e participativo.

Particularmente, a PNAS (BRASIL, 2004) apresenta uma definição de um modelo de gestão descentralizado e participativo, que passou a ser denominado de Sistema único de Assistência Social (SUAS). Neste Sistema, está previsto que os serviços, programas, projetos e benefícios sócio assistenciais tenham como foco prioritário às famílias, seus membros e indivíduos e o que o território seja a base de organização. Além disso, que essas estratégias sejam definidas pelas funções que desempenham, pelo número de pessoas que deles necessitam e pela sua complexidade. Este Sistema pressupõe, ainda, gestão compartilhada, co-financiamento da política e definição das competências técnico-políticas da União, Estados, Distrito Federal e Municípios, com a participação e mobilização de representantes governamentais e da sociedade civil, que tem um papel importante na sua implantação e implementação (BRASIL, 2004).

Porém, desde o meado dos anos 1990, o governo federal criou impulsos de centralização política e financeira, como a Lei de Responsabilidade Fiscal de 2000, alegando que a descentralização fiscal prevista na Constituição de 1988 possibilitou o abuso de poder estatal nos níveis regionais/locais, que trouxe prejuízo à política macroeconômica recomenda pelo Banco Mundial e FMI. As autoridades e técnicos que atuavam na área econômica da União frequentemente os acusavam de práticas clientelistas e de não combaterem ou até mesmo de gerarem o déficit público. A ideia era garantir que a União, por meio de metas superavitárias que não efetivavam direitos sociais, destinasse parcelas generosas dos recursos orçamentários para honrar com o pagamento de juros e encargos da dívida pública (SILVA, 2016).

Entretanto, esse movimento não se deu ou não vem ocorrendo sem resistência política. Uma frente de prefeitos e governadores tem defendido um federalismo descentralizante, embora pouco democratizante. Por outro lado, setores progressistas da sociedade buscam pôr em prática a tendência descentralizadora incorporada na Constituição de 1988. A hipótese de Fiori (1992), assim, se confirma. No cenário contemporâneo, há duas perspectivas fundamentais: a primeira hegemônica caracteriza-se pela reconcentração do poder político-administrativo no governo federal com base uma recentralização fiscal, mas 


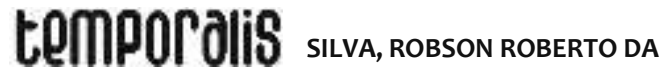

sofre críticas de certos dirigentes subnacionais que sustentam suas proposições na tese liberal de federalismo; e a segunda perspectiva exige uma desconcentração cada vez mais sólida do poder e recursos fiscais (SILVA, 2016).

No âmbito da PNAS/SUAS, apesar da descentralização corresponder, no campo normativo e legal, à redistribuição de poder entre as esferas de governo e entre Estado e organizações e espaços públicos da sociedade civil, na prática, ela vem se efetivando como uma transferência de responsabilidade, sem o repasse na mesma medida de autonomia e de recursos financeiros, do governo federal para os estados e principalmente para municípios; e do Estado para organizações e entidades privadas de assistência social. Essa transferência de responsabilidade tem sido feita por meio da delegação de funções de gestão e/ou da privatização, que nessa área vem se expressando através das terceirizações, das parcerias público-privadas e dos incentivos jurídicos e financeiros para organizações e entidades privadas de assistência social.

Embora determinados estados e municípios tenham criado alguns projetos, programas e benefícios assistenciais, tomando como referência as particularidades locais, as principais iniciativas implementadas por esses governos regionais e locais foram e são elaboradas pelos ministérios e órgãos federais nos diferentes mandatos. Destacam-se no nível da proteção social básica as ações executadas pelos CRASs, como o Programa Bolsa Família, cadastramento do Minha Casa, Minha Vida, Plano Brasil sem Miséria, Criança Feliz, Serviço de Convivência e Fortalecimento de Vínculos para Adolescentes e Jovens, de Proteção e Atendimento Integral à Família, Passe Livre Interestadual e Benefício de Prestação Continuada; e no nível da proteção especial, as ações implementadas pelos CREASs, como Programa de Combate ao Abuso e Exploração Sexual; e o de Erradicação do Trabalho Infantil. A execução deste conjunto de programas e serviços pré-formatados vem sendo delegada aos estados e municípios e com dotação orçamentária já vinculada, impedindo remanejamento no uso dos recursos.

Assim, nota-se uma nítida separação entre a esfera responsável pela formulação (o governo federal) e a esfera destinada a implementação das ações de proteção social no SUAS (os governos estaduais e sobretudo os municipais), que é um dos mecanismos do gerencialismo, assim como a centralização, a desconcentração, a delegação, as parcerias público-privadas, as privatizações, as mudanças de gestão hierárquica para gestão por contrato, a redução do poder de auto-regulamentação de profissionais, o aumento do ritmo de trabalho etc. (SILVA, 2014; 2016). Além desses mecanismos gerenciais, Bento (2003) destaca o aumento dos controles financeiros; a criação de sistemas de informação; racionalização orçamentária; uma política de eficiência; a administração voltada a objetivos e metas organizacionais associadas à gestão de desempenho, acompanhamento e controle; a delegação; e atribuição de responsabilidade para os agentes delegados quando da má gestão de programas e serviços.

Na PNAS/SUAS, os sistemas de informação e outras tecnologias adotadas vêm se configurando, principalmente, como um mecanismo gerencial, na medida em que promovem a intensificação do trabalho, o aumento da fiscalização e a avaliação por desempenho. A própria engenharia criada para por em prática o Índice de Gestão Descentralizada (IGD) do Programa Bolsa Família (PBF) apresenta traços desse padrão de administração e serviu como experiência para criação do IGD-SUAS, instituído pela Lei n. ${ }^{\circ}$ 12.435, de 6 de julho de 2011 e regulamentado pelo Decreto n. ${ }^{\circ} 7.636$, de 7 de dezembro 
deste mesmo ano, que dispõe sobre o apoio financeiro da União à gestão descentralizada deste Sistema. Assim como o IGD do PBF, este índice também trabalha a variação entre 0 (zero) a 1 (um), mas distintamente possui duas modalidades: IGD-SUAS-Municipal e IGDSUAS-Estadual, cujos cálculos levam em consideração o Índice de Desenvolvimento do CRAS (ID-CRAS) e a execução financeira dos fundos de assistência social (Brasil, 2012).

A transferência de recursos financeiros pela União só ocorre se os estados, o Distrito Federal e municípios alcançarem o índice superior a 0,2 (dois décimos). Para não caracterizar Caixa 2, os governos devem utilizar os recursos para o aprimoramento da gestão e da organização do SUAS. Por mais que a União considere que o IGD-SUAS seja um mecanismo indutor do alcance das metas pactuadas nacionalmente para 0 aperfeiçoamento da gestão deste Sistema e da qualidade dos seus serviços prestados à população, ele na verdade traduz-se num instrumento que opera sob uma lógica hierarquizada, que centraliza e transfere recursos, a partir do cumprimento de metas, a um conjunto de ações implementadas pelos governos estaduais e municipais, como os programas e benefícios nacionais de transferência de renda condicionada, colocando como elemento central nos equipamentos públicos de assistência social a lógica produtivista, que intensifica o trabalho e que valoriza um saber instrumental (SILVA, 2014). Por essa razão, é preciso:

[...] resistir coletivamente ao mero produtivismo quantitativo, medido pelo número de reuniões, número de visitas domiciliares, número de atendimentos, número de cadastros, sem que o profissional tenha clareza do sentido e da direção social ético-política do trabalho coletivo. Por sua vez é nesse âmbito, de ampliação das metas a serem atingidas, que se instalam as estratégias de intensificação do trabalho, potencializadas pelas mudanças tecnológicas nem sempre sob controle dos trabalhadores (RAICHELIS, 2011, p. 58).

Em um contexto extremamente adverso, a PNAS (2004) inovou ao eleger a política de recursos humanos como um dos eixos estruturantes do SUAS, tendo em vista que a descentralização da sua gestão exige, além do compromisso com a política como direito social, a capacitação de forma sistemática e contínua, e a valorização do serviço público e de seus trabalhadores, com a criação de plano de carreira e concursos públicos, que venham enfrentar a precarização do trabalho. Em função dessas exigências, a Resolução $n^{\circ}$ 269, de 13 de dezembro de 2006, do Conselho Nacional de Assistência Social (CNAS), aprovou a Norma Operacional Básica de Recursos Humanos do SUAS (NOB-RH/SUAS). No entanto, a gestão do trabalho neste Sistema tem sido fundamentada por distintos processos sociais, como a restruturação produtiva que levou setores conservadores a demandaram uma contrarreforma do Estado e da administração pública nos moldes do gerencialismo.

Segundo lasi (2012), "[...] não há nenhuma coincidência no fato de que o processo de reestruturação produtiva se combine com a insistente demanda dos setores conservadores pela chamada 'reforma do Estado' [...]" (IASI, 2012, p. 56), que ocupa um papel central no conjunto das mudanças promovidas pela neoliberalização. Por meio dessa contrarreforma do Estado e da administração pública inspirada no gerencialismo acentuase a precarização das condições e relações de trabalho, pois nas três esferas de governo diminuem os concursos públicos, que, quando acontecem, o quantitativo de vagas não corresponde as reais necessidades institucionais, reduzem as contratações, que ocorrem 
cada vez mais por meio de terceirizações, contratos temporários; e aumentam as demissões (SILVA, 2014). Nessa mesma direção, Raichelis (2011) aponta que:

A reforma neoliberal do Estado brasileiro implantada, nos anos 90, cujos efeitos se fazem sentir na realidade atual, sintetizada no fortalecimento da 'cultura do gerencialismo', trouxe também intensa campanha ideológica de desconstrução do Estado e de 'tudo que é estatal', atingindo duramente as condições e relações de trabalho nos espaços governamentais (RAICHELIS, 2011, p. 54, grifos nossos).

Raichelis (2011) ainda destaca que esse é um desafio para toda a administração pública no Brasil. Porém, assume características específicas na área de assistência social, tendo em vista o seu histórico de desprofissionalização e de atuação com base em estruturas improvisadas, descontínuas e impregnadas da cultura autoritária, patrimonialista e assistencialista, cuja expressão mais emblemática encontra-se no chamado primeirodamismo. A autora acrescenta que a maioria dos municípios é de pequeno porte e possui uma estrutura institucional frágil, com rotinas técnicas e administrativas incipientes e recursos humanos reduzidos e pouco qualificados. Além disso, são dependentes das transferências federais e estaduais. Destaca ainda que o quadro profissional do SUAS é constituído por um universo heterógeno de trabalhadores e por uma extensa rede privada de entidades de assistência social, com uma diversidade de áreas de formação, projetos profissionais, acúmulo teórico-prático, vínculos e condições de trabalho.

A respeito da chamada rede privada de entidades de assistência social, historicamente essas entidades têm sido classificadas como as maiores prestadoras de serviços nessa área social. A primazia do Estado prevista pela LOAS (1993) e pela PNAS/SUAS (2004) não significou e também não tem resultado numa laicização e estatização dessa política social. A maioria das instituições de assistência social ainda hoje é de natureza privada. Estudos divulgados pelo IPEA (2007) demonstram que o financiamento indireto do Estado para essas entidades e organizações é cinco vezes maior do que os recursos disponibilizados pelo Fundo Nacional de Assistência Social para a execução de serviços sócio assistenciais. O Censo SUAS (BRASIL, 2014) aponta que em 2014, 36,2\% dos órgãos gestores municipais informaram ter feito transferências de recursos via convênio para ONGs ou entidades sócio assistenciais. Destes municípios, 51,6\% aproximadamente o fazem com recursos do próprio Fundo Municipal de Assistência Social, 17,6\% com recursos de outras fontes e 30,7\% com recursos tanto do Fundo quanto de outras fontes.

De acordo com ideólogos do gerencialismo, o Estado, ao incentivar legalmente e financeiramente as organizações não governamentais, que julgam ser sem fins lucrativos, voltadas para o interesse geral e que são regidas pelo direito privado, torna-se menos burocrático e ineficiente, combate o fisiologismo, introduz a competição e a flexibilização na provisão dos serviços sociais, como também amplia os canais capazes de intermediar os conflitos sociais no próprio Estado e na sociedade civil (BRESSER PEREIRA; GRAU, 1999). Por essa razão, não resta dúvida de que o Estado incentiva a participação com o interesse de cooptar/neutralizar determinadas forças sociais, de convertê-la em parceria, de reduzir sua execução a tarefas burocráticas e de estimular práticas solidárias (cf. NOGUEIRA, 2005). A participação assume assim uma funcionalidade gerencial, na medida em que contribui com a privatização e administração dos conflitos. Nos termos de um defensor do gerencialismo, "[...] a participação tem uma legitimidade macroeconômica e gerencial" (KLIKSBERG, 2005, p. 67, grifos nossos). 


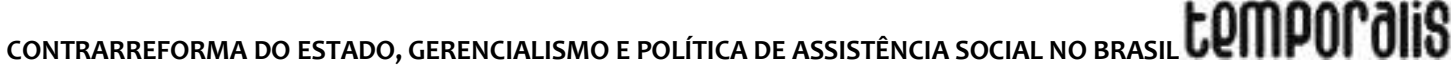

Segundo Silva (2014), a expansão dos espaços de participação no âmbito nacional nos governos do PT configurou-se como uma estratégia do governo de controlar politicamente uma parcela dos movimentos sociais e sindical por meio da cooptação. A grande maioria dos conselhos construídos ou reativados assumiu o caráter consultivo e passaram a ser chamados pelo governo de espaços de interlocução. A ideia por trás disso era de que a participação com vistas à decisão se restringisse ao sistema eleitoral, pois os mecanismos de controle no gerencialismo são: o mercado; o controle hierárquico gerencial; a democracia representativa e a democracia direta (cf. BRESSER PEREIRA, 1997). Esse último mecanismo, de acordo com essa concepção de participação, só pode ser realizado através de conselhos consultivos ou espaços de interlocução, que visam orientar as decisões dos representantes governamentais eleitos pela democracia representativa. Não é por acaso, que o ex-chefe do MDS, Patrus Ananias de Sousa, propôs em 2007 que os conselhos deliberativos como o CNAS assumissem o caráter consultivo (SOUSA, 2007). Ainda hoje determinados sujeitos que participação dos conselhos de assistência social nas três esferas de governo desqualificam como consultivos esses espaços legalmente instituídos como deliberativos.

Em 2019, o governo Bolsonaro, por meio do Decreto № 9.759, de 11/04/2019, procurou reduzir drasticamente o número de espaços de participação instituídos por meio de decretos, como os conselhos previstos pela Política Nacional de Participação Social e pelo Sistema Nacional de Participação Social, que foram criados no governo Dilma. De acordo com a matéria do Jornal O Globo (SACONI; ALEIXO; MAIA, 2019), a partir do levantamento realizado pelo Ministério da Economia, mais de 700 espaços foram extintos sob a justificativa do governo de desburocratizar, racionalizar os gastos e enfrentar uma suposta visão ideológica mantida pelas gestões anteriores. Em síntese, nota-se que, sem colidir com determinados aspectos da ordem patrimonial-burocrática (como a exclusão da participação dos trabalhadores nos processos decisórios), o governo Bolsonaro vem buscando adequar a administração pública ao padrão gerencialista, como forma de contribuir com o ajuste fiscal.

\section{CONSIDERAÇÕES FINAIS}

Assim, pôde-se notar neste trabalho que a contrarreforma do Estado e da administração pública inspirada no gerencialismo não se limitou aos governos de FHC e vem contribuindo com o ajuste fiscal permanente. $O$ próprio Bresser Pereira, principal mentor dessa proposta contrarreformista dos anos 1990, considerou que os "[...] avanços continuam ocorrendo, não apenas no nível federal, mas também no estadual e no municipal, pois a reforma de 1995 modificou a pauta da administração pública em todo o país" (BRESSER-PEREIRA, 2009, p. 254).

De acordo com Souza Filho (2011), essa contrarreforma vem contribuindo com o ajuste fiscal a partir de dois mecanismos: o primeiro está voltado, por um lado, para a redução do aparelho do Estado, via privatização, terceirização, extinção de órgãos e focalização dos gastos sociais e, por outro lado, para a centralização e fortalecimento dos núcleos de decisão e controladores das políticas (núcleos estratégicos); e o segundo busca reorganizar a relação entre formulação e implementação de políticas, redefinindo a relação de controle, através da descentralização e estabelecimento de critério de performance, 
que seriam acompanhados via contratos de gestão a partir da transformação de determinados órgãos em organizações sociais ou em agências executivas.

No processo de implementação da PNAS/SUAS notou-se que, embora a gestão dessa política social seja marcada por traços de um projeto de assistência como direito e dever do Estado, as marcas de um projeto hegemônico neoliberal de assistência social, que conserva aspectos de um projeto tradicional, se fazem mais presente. Por pressupor o gerencialismo como um modelo ideal de gestão, esse projeto hegemônico vem se efetivando de modo a atender os interesses da classe dominante e suas frações. No que diz respeito às principais incidências do gerencialismo na implementação da PNAS/SUAS pôde-se aqui demonstrar: a centralização do poder na União; a separação entre órgãos formuladores e implementadores; descentralização (como sendo delegação, privatização e/ou transferência de responsabilidade); a defesa dos conselhos como consultivos ou espaços de interlocução; a terceirização; avaliação por desempenho; produtividade; criação e uso nessa direção de sistemas de informação; e a valorização do saber burocrático/instrumental.

\section{REFERÊNCIAS}

AGUIAR, C. A. M. Administração pública. In: DI GIOVANNI, G. e NOGUEIRA, M. A. (org.). Dicionário de políticas públicas. São Paulo: Editora da UNESP; FUNDAP, 2015.

ANTUNES, R. A desertificação neoliberal no Brasil (Collor, FHC e Lula). São Paulo: Autores Associados, 2005.

BEHRING, E. R. A dívida e o calvário do fundo público. ADVIR (ASDUERJ), Rio de Janeiro, V. 36, 2017.

BEHRING, E. R. Brasil em contra-reforma: desestruturação do Estado e perda de direitos. São Paulo: Cortez, 2003.

BENTO, L. V. Governança e governabilidade na reforma do Estado: entre eficiência e democratização. São Paulo: Manole, 2003.

BRASIL. Ministério do Desenvolvimento Social. Censo SUAS 2014. Brasília (DF), 2014.

BRASIL. Ministério do Desenvolvimento Social. Política nacional de assistência social. Brasília (DF), 2004.

BRASIL. Ministério do Desenvolvimento Social e Combate à Fome. Caderno de orientações sobre o índice de gestão descentralizada do sistema único de assistência social - IGDSUAS. Brasília (DF), 2012.

BRESSER PEREIRA, L. C. Construindo o Estado republicano: democracia e reforma da gestão pública. Rio de Janeiro: FGV, 2009.

BRESSER PEREIRA, L. C. A reforma do Estado dos anos 90: lógica e mecanismos de controle. Cadernos do MARE da reforma do Estado, Brasília (DF): MARE, 1997. 


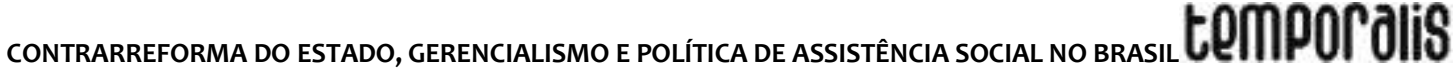

BRESSER PEREIRA, L. C.; GRAU, N. C. Entre o Estado e o mercado: o público não-estatal. In: O PÚBLICO não-estatal na reforma do Estado. Rio de Janeiro: Fundação Getúlio Vargas, 1999.

CASTELO, R. O novo desenvolvimentismo e a decadência ideológica do pensamento econômico brasileiro. Serviço Social e Sociedade, São Paulo, n. 112, p. 613-636, out./dez. 2012.

COLLOR, F. Brasil: um projeto de reconstrução nacional. Brasília (DF): Senado Federal, 2008.

COUTINHO, C. N. A hegemonia da pequena política. In: OLIVERIA, F. de; BRAGA, R. e RIZEK, C. (orgs.). Hegemonia às avessas: economia, política e cultura na era da servidão financeira. São Paulo: Boitempo, 2010.

DARDOT, P.; LAVAL, C. A nova razão do mundo: ensaio sobre a sociedade neoliberal. São Paulo: Boitempo, 2016.

FIORI, J. L. O Estado brasileiro do futuro: descentralização ou desintegração. Rio de Janeiro: UERJ; IMS, 1992.

HARVEY, D. O neoliberalismo: história e implicações. São Paulo: Edições Loyola, 2008.

IASI, M. L. O fascismo e os "homens bons". Blog da Boitempo, São Paulo, 16 out. 2018. Disponivel em: https://blogdaboitempo.com.br/2018/10/16/o-fascismo-e-os-homens-bons/. Acesso em: 1 mar. 2019.

IASI, M. L. O Estado depois do ajuste: políticas sociais na época da hipocrisia deliberada. In: PASTORINI, A. et al. Estado e cidadania: reflexões sobre as políticas públicas no Brasil contemporâneo. Rio de Janeiro: Editora FGV, 2012.

INSTITUTO DE PESQUISA ECONÔMICA APLICADA. Assistência social e segurança alimentar. Políticas sociais - acompanhamento e análise, Brasília: IPEA, n. 14, 2007.

KLIKSBERG, B. Como por em prática a participação? Algumas questões estratégicas. In: CADERNOS da fundação Luís Eduardo Magalhães - gestão pública e participação, Salvador: FLEM, 2005.

LIMA JÚNIOR, O. B. de. As reformas administrativas no Brasil: modelos, sucessos e fracassos. Revista do serviço público, Brasília: ENAP, ano 49, n. 2, abr./jun. 1998.

MÉSZÁROS, I. A montanha que devemos conquistar: reflexões acerca do Estado. São Paulo: Boitempo, 2015.

MOTA, Ana Elizabete. Redução da pobreza e aumento da desigualdade: um desafio teórico-político ao Serviço Social brasileiro. In: MOTA, Ana Elizabete (org.).

Desenvolvimento e construção de hegemonia: crescimento econômico e reprodução da desigualdade. São Paulo: Cortez, 2012. 
NOGUEIRA, M. A. Um Estado para a sociedade civil: temas éticos e políticos da gestão democrática. São Paulo: Cortez, 2005.

PAULA, A. P. P. de. Administração pública brasileira entre o gerencialismo e a gestão social. RAE, v. 45, n. 1, 2005.

RAICHELIS, R. O trabalho e os trabalhadores do SUAS: o enfrentamento necessário na assistência social. In: BRASIL. Ministério do Desenvolvimento e Combate à Fome. Gestão do trabalho no âmbito do SUAS: uma contribuição necessária. Brasília (DF), 2011.

SACONI, João Paulo; ALEIXO, Isabela; MAIA, Gustavo. Decreto do governo Bolsonaro mantém apenas 32 conselhos consultivos. Jornal O Globo, Rio de Janeiro, 29 jun. 2019. Disponível em: https://oglobo.globo.com/brasil/decreto-do-governo-bolsonaro-mantemapenas-32-conselhos-consultivos-23773337. Acesso em: 6 fev. 2020.

SILVA, R. R. da. A seguridade social em disputa no Brasil. Praia vermelha, v. 28, n. 1, p. 147-174, 2018.

SILVA, R. R. da. Descentralização no Brasil: determinantes que limitam a sua efetivação. Argumentum, Vitória, v. 8, p. 167-180, maio./ago., 2016. Disponível em: http://periodicos.ufes.br/argumentum/article/view/11664/9956. Acesso em: 6 fev. 2020.

SILVA, R. R. da. (Des)centralização, contrarreforma do Estado e política de assistência social no Brasil. 2014. Tese (Doutorado em Serviço Social) -Escola de Serviço Social da Universidade Federal do Rio de Janeiro, Rio de Janeiro, 2014.

SOUSA, Patrus Ananias de. Ver as árvores e enxergar o bosque. Jornal Valor Econômico, São Paulo, edição de 10 a 12 ago. 2007.

SOUZA FILHO, R. de. Gestão pública e democracia: a burocracia em questão. Rio de Janeiro: Lumen Juris, 2011.

SOUZA FILHO, R. de.; GURGEL, C. Gestão democrática e serviço social: princípios e propostas para a intervenção crítica. São Paulo: Cortez, 2016. (Biblioteca Básica do Serviço Social).

\footnotetext{
Robson Roberto Silva

Possui graduação em Serviço Social (2005) e mestrado em Política Social (2007), ambos pela Escola de Serviço Social (ESS) da Universidade Federal Fluminense (UFF). É especialista em Serviço Social, Direitos Sociais e Competências Profissionais (2010) pela Universidade de Brasília (UNB). Doutor em Serviço Social pelo Programa de Pós-graduação em Serviço Social da Universidade Federal do Rio de Janeiro (UFRJ). Professor Adjunto da ESS da UFF de Niterói, onde participa como pesquisador do Grupo de Pesquisa sobre Política Social e Desenvolvimento (GPODE). Tem experiência profissional em ensino na área de Fundamentos de Serviço Social e em pesquisa e extensão relacionadas às políticas sociais e aos espaços sócio-ocupacionais de atuação dos assistentes sociais. Sua produção acadêmica concentra-se nas áreas: avaliação e gestão de politicas sociais; seguridade social e política de assistência social; e Serviço Social.
} 